\title{
The Investigation of Pragmatic Transfer in the Speech Act of Congratulations by Punjabi EFL Learners
}

\author{
Asif Aziz ${ }^{1}$, Binish Maqsood ${ }^{1}$, Tahir Saleem ${ }^{1} \&$ Summiya Azam $^{1}$ \\ ${ }^{1}$ University of Central Punjab, Lahore, Pakistan \\ Correspondence: Summiya Azam, University of Central Punjab, Lahore, Pakistan. E-mail: \\ summiyatahir@yahoo.com
}

Received: April 6, 2018 Accepted: June 9, 2018 Online Published: September 1, 2018

doi:10.5539/ijel.v8n6p240 URL: https://doi.org/10.5539/ijel.v8n6p240

\begin{abstract}
This paper investigates pragmatic transfer in Punjabi EFL learners' realization of the speech act of congratulations. For this purpose, 120 participants were asked to take part in the study, who were divided into four groups having 30 participants in each group: 30 native English (NE) speakers, 30 Punjabi EFL learners of the elite class, 30 Punjabi EFL learners of the middle class and 30 Punjabi EFL learners of the lower class. To elicit the data, a DCT having 12 situations based on social power and distance was used and for perception data, these situations were analyzed on the basis of four contextual variables (degree of familiarity, power, difficulty, and obligation in expressing congratulations) in the form of SRQ. The criteria for the analysis of negative pragmatic was set on the differences found in the responses of the participants and the positive pragmatic transfer was based on the similarities between the responses of the participants. The data was coded and analyzed under the taxonomy of congratulations proposed by Elwood (2004). The results of the study indicated the presence of negative pragmatic transfer in three different strategies of congratulation (IFID, OOGW and Overlapped) and the remaining of the strategies indicated the existence of positive pragmatic transfer. The findings of the study show the cultural influence on the use of congratulation strategies by Punjabi EFL learners. The results of the study might be pedagogical significance and could prove helpful for policymaker and syllabus designer as well within Pakistani context.
\end{abstract}

Keywords: pragmatic transfer, congratulation, positive and negative pragmatic transfer, pedagogical significance, Punjabi EFL learners

\section{Introduction}

Second language pragmatics is also known as Interlanguage Pragmatics. It is a coined term of two different research traditions: Interlanguage and Pragmatics. The concept of "Interlanguage Pragmatics" for the first time was coined by Selinker (1972) in order to represent the Livermore system which a probationer construct in single stage at a particular time (one interlingua) and a number of interrelated orders which constitutes the learners' developmental progress over a period of time (as cited in Ellis, 1994, p. 350). According to Blum-Kulka and Kasper (1993), ILP is regarded as a mixed expression of second-generation research paradigms namely, second language acquisition and Pragmatics. In ILP studies, the researchers tried to investigate the production, perception, and development of learners' pragmatic abilities in terms of linguistic actions (speech acts) (Kasper, 1988). In early studies in the area of Interlanguage Pragmatics, much importance was given to conventional features of communicative acts (e.g., grammar, ways of producing utterances, word formation, and sentence formation) but due to the recent shift from communicative to pragmatic competence, the dimensions of research in ILP has been changed.

Kasper (1992, p. 203) defined Intercultural pragmatics as "the branch of research in which studies about the second language are done, and such studies deal with EFL learners-understanding and performing communicative acts within the boundaries of foreign language and how the learners gain insight into the pragmatic competence of target language". It implies that the central focus in the area of ILP is regarded as the realization (perception and comprehension) of the speakers' interlanguage in respect of contextual standpoint at one side while on the other hand mechanism which is involved in the acquisition of the pragmatic categories on the second language on the other hand. Accordingly, scholars (Kasper \& Blum-Kulka, 1993; Torborg, 1995) mentioned that Intercultural pragmatics refers to the investigation of learners' pragmatic competence of their 
target language (L2), whose concept is contrasted with learners' grammatical competence in L2. In their studies, they discussed that there are three major areas of research in the field of ILP are contextual apprehension; performance of linguistic action; development of contextual knowledge and performative effects. Therefore, the goal of this study was to consider the influence of native language in interlanguage pragmatics, which implies that "pragmatic displacement" is studied in the light of the structure of intercultural and cross-cultural studies. Such as Kasper and Schmidt (1996, p. 150) have said "up-to-date, the influence of contextual transparency was the only specific problem for inter-lingual studies that received sustained attention in ILP and, therefore, aligns ILP with the main research of second language acquisition."

It is generally assumed that, the speaker of one language (L1) when acquiring another language (L2) he or she is not familiar with the rules governing L2, due to which they pragmatically transfer some elements of their culture into the production of L2. This phenomenon is commonly known as a pragmatic transfer (L1 learners' pragmatic and cultural knowledge exerts the influence on the comprehension and production of L2). There are many studies conducted related to the notion of pragmatic transfer with respect to different speech acts, which stated that the transfer of pragmatic knowledge of L1 into L2 resulted into serious issues such as, pragmatic failure, communication breakdown, communication errors etc. Due to which, this area attracted the attention of many researchers in the domain of interlanguage pragmatics and it has become quite necessary to investigate the language learning and acquisition on behalf of the EFL learners. Therefore, keeping in mind the present situation of teaching and learning of the second language within Pakistani context; in the present study, the realization of speech acts of "congratulating" were examined; in order to investigate the notion of pragmatic transfer in congratulation strategies realized by Punjabi EFL learners. The researchers also tried to investigate the effect of the culture of L1 in the realization of congratulation in L2 because it is generalized that there is found as the inseparable relationship between culture and language. Byram and Feng (2005) argued that intercommunication is considered as one of the most intricate situations which demands both internal and external features (setting, participants, and culture) which in turns plays a significant role in the consummation of conversation within a particular social context. Alainsom $(1999$, p. 632) argued that the fact is inevitable because not only do we exist in culture on the other hand "we live culturally" which means that we are being affected and swayed through culture or reproduce cultural constituents and actively perform actions as being the past of the society in which we exist. As Irving pointed out that culture is an element that enables an individual to frame societal communication, with the help of which he is able to capture the true picture of the society that surrounds him. Furthermore, it is stated that it is culture that prescribes the norms of communication such as who speaks to whom, which type of repertoire is required and how conversation is carried out, it also governs the rules and regulations under which people encode and decode the messages and the information that they want to convey to others. It also helps the interlocutor how to perform in a particular setting.

Barna (1997) noticed that where culture provides us sight to the world around us, at the same time, it makes us sightless. In the sense that we produce utterances based on our culture habitually without considering the asymmetry of acts performed in a distinct culture because it is assumed that each and every culture equipped with different beliefs and customs in contrast to other. Therefore, each speech community has its own rules and verbal repertoires in order to carry out a successful conversation. While in the acquisition of the second language, the elocutionist tends to assume that there are found similarities among the culture of his own and acquiring one. This assumption leads towards the ignorance of other culture's norm of communication, which later results in miscommunication, it could be miniaturized by gaining insight into the cultural analogy and dissimilarities. It is observed that civilization and cognizance are connected with each other because it is a culture that shapes the mental illustrations or depiction of the world around us that helps in shaping and producing the cultural schema according to which we survive in that particular culture.

\section{Literature Review}

Congratulation as the focal point around which the present study rotates, is regarded as "Behabitives" in the light of the classification of illocutive acts put forwarded in the influential work of Austin (1962), while on the other hand in light of the taxonomy of speech acts propounded by Searle (1969), it is regarded as an expression in nature. Behabitives allude to the expressions that are used to demonstrate the attitudes and reaction of someone about something in an appropriate context (Austin, 1962). Similarly, expressions are used to refer to the feelings and psychological state of the speaker toward a particular situation in a particular setting (Searle, 1969). Searle (1979) argued that in the act, the elocutionist does not try to make words conform to words or words to the worlds. For this reason, an individual utters the expression "congratulations to you to be victorious in the competition of race" instead of "me congratulate you for winning the race" (p. 158). 
Therefore, it is claimed that expressions do not have to fulfill the condition of fit because it is considered as the nitty-gritty values of an articulated linguistic expression based on the presuppositions related to the produced utterance. As a result, Searle (1979, p. 158), regarded the illocutive point of the produced linguistic expression as the subconscious frame of mind which is particularized in the probity conditions in respect of the scenario represented in the nominal essence of the utterance. Taking the aforementioned notion into account, Searle (1969) develops certain rules for the linguistic act of congratulation:

1) Nominal contact principle: a certain, event, a particular action, occasion, etc, the event (E) should be associated with the hearer $(\mathrm{H})$.

2) Precautionary principle: the event (E) should be related to the hearers' (H's) interest and the elocutionist should be certain of the view that, the event is in hearers' concern.

3) The principle of earnestness that is a speaker (S) is satisfied with that particular event.

4) It should be regarded as the visage of happiness about a particular event (E).

Interlanguage pragmatics is a discipline in which the central focus is given to the notion of pragmatic transfer. The concept of pragmatic transfer was first introduced in the interim of the period of Conversational Analysis (SA) that is related to the behaviorist approach towards the acquisition of second language and structural linguistics. Due to the astonishing influence of the native on the realization of speech acts in the target language, primarily at the level of pronunciation, led the scholars to build the foundations for the formulation of Contrastive Analysis Hypothesis in the 1960s. In the past, there were two convictions about acquisition and language learning: firstly, the speaker's LN had a strong influence on L2 and, secondly, the influence of the second language was considered to be negative. Furthermore, researchers believed that whenever two languages are different from each other, there would be negative transfer because speakers' native language influenced speakers' use of the second language, which led towards miscommunication and speaker would produce errors during their conversation.

In the early 1970s, CA and behaviorism face shortcomings and CAH became insupportable empirically and theoretically. The change in the perspectives on language learning was mainly brought by Chomskyian Cognitive view of language learning. Chomskyian Cognitive structure towards SLA stressed the development goal of acquiring more than the influence of L1 on the acquisition of L2 language rather than the influence of L1 on the acquisition of L2. The concept of pragmatic transfer was defined by Kasper (1992) in these words "the effects produced due to the learner's cultural norms and contextual competences on the perception, performance and their acquisition of foreign language knowledge" (p. 207). In the light of the aforementioned groundwork, Kasper differentiated positive pragmatic transfer from the negative pragmatic transfer. Pragmatic transference is considered positive in the sense that it aids the learning process of target language such as that "the specific usage of language conventions and the realization of language are not manifestly universal, but mutually acknowledged in both languages; L1 and L2" (p. 212). While at the other corner is the notion of negative pragmatic transfer, which consequently moves the speaker towards the production of communicative errors when pragmatic standards based on L1 "project in L2 communicative settings and different perceptions and pragmatic behaviors of the community of reference" (Kasper, 1992, p .213). The negative pragmatic transfer has been given more importance because of its abilities for pragmatic failure.

On the basis of Leech (1983) and Thomas' (1983) categorization of pragmatics, the concept of pragmatic transfer was divided into the pragmalinguistic transfer and sociopragmatic transfer by Kasper, which was based on the concept that there is found an inseparable relationship between culture and society. The division of metapragmatic transfer including both socio-pragma-linguistic transference is significant not only in the formalistic sense with the dimensions of cross-cultural pragmatics but it holds great importance as the framework employed by the researchers in the field of Interlanguage Pragmatics particularly for the investigation of pragmatic transfer. The term "pragma-linguistic transfer" means the process by which illocutive or sustained linguistic values over a particular material in native language influences perception and production of form-function mapping in L2 (Kasper, 1992, p. 209). As for the notion of sociopragmatic transfer is concerned, he explained it with these words; the socio-strategic transfer, at that moment, is in action whereas the social conceptions cardinal to the interpretation of the users of the language and the performance of linguistic action L2 and affected by their evaluation of the subjectively equivalent L1 contexts (Kasper, 1992, p. 209).

The major concern in the field of research related to the concept of contextual transference regarded as the mechanism which is utilized in the analysis of pragmatic transference. As Kasper (1992) proclaimed so, in most of the contextual transfer investigation no well-sounded methods had established for the measurement of pragmatic transfer. For this purpose, a number topics related to the concept of probability were established on the 
colloquial approximation of the similarities and the differences in the percentages with which peculiar strategies (linguistic acts) exists in native language, target language, and intercultural data. Therefore the aim of the present research work was to analyze the notion of pragmatic transference at sociopragmatic and pragma-linguistic level. Pragma-linguistic transfer put emphasize on the use of the use of linguistic strategies, while, sociopragmatic transfer focuses on the investigation of perception and utterance of linguistic acts congratulation. Two contextual variables as social status and societal power were used simultaneously for the code of analysis which will be used for the measurement of performative data. As far as the analysis of comprehension of data to be accounted for, it further measures pragmatic transfer in terms of contextual variables e.g., right, difficulty in addition to social distance and power that cannot be measured by the speaker's performance.

\subsection{Studies on Pragmatic Transfer}

A number of studies related to the concept of pragmatic transfer were conducted. Yarahmadi and Fathi (2016) conducted a study to investigate the notion of pragmatic transfer. They tried to investigate this critical phenomenon with respect to complaint strategies employed by Persian-speaking students (EFL students). The findings of their study were based on the similarities and differences among the participant related to the production of complaint SAs with respect to the choice and frequencies of the strategies used. It was also found that the degree of familiarity and the degree of power also influenced the production of the participants in L2. On the basis of their interpretation of the analyzed data, they argued that pragmatic transfer existed in L2 production and Iranian learner need to be enriched with more knowledge of L2 in order to use complaint strategies with inappropriate context.

A similar study related to the investigation of pragmatic transfer in refusal speech acts was carried out by Jiang (2015), in which he tried to investigate the realization of the speech act of refusal in order to examine the pragmatic transfer. The participants of the study were three groups divided into the native speaker of Chinese, English learner of Chinese and native speakers of English. A written DCT was used by the researcher for data collection purposes. He compared the performance data of the participants so that the similarities and differences could be marked in the use of refusal strategies employed by a native English speaker and a native speaker of Chinese. The results of the study revealed that the native English speaker uses more direct strategies of refusal as compare to a Chinese speaker. Pragmatic transfer was apparent in the responses in terms of frequency of the use of refusal semantic formulas. The findings also revealed that the overall correlation between the responses of the participants was negative.

A related study to pragmatic transfer was conducted by Hashemain (2012), in which he tried to investigate the cross-cultural differences along with pragmatic transfer in terms of English and Persian speech act of Refusals. The findings of the study did not show any significant point of differences in the use of refusal strategies by both groups of the participants. As compared to this, PNSs used mostly indirect strategies while ENs used adjuncts category of refusal. This point of difference showed the existence of pragmatic transfer in their realization of the speech act of refusal.

$\mathrm{Bu}$ (2012) in his study investigated the phenomenon of pragmatic transfer in the speech acts of suggestion used by the Chinese learners of English. The findings of the study revealed that pragmatic transfer exists which is considered as the result of cultural values of Chinese.

To the researchers' best knowledge and as evident from above-mentioned studies, no study was conducted related to the speech act of congratulation as far the notion of pragmatic transfer is concerned. Therefore, in the present study, the researchers tried to investigate the notion of PT employed by the Punjabi EFL students in the utilization of congratulation schemes, which would help to fill the gap in the research area on the congratulatory speech in terms of the pragmatic transfer. As mentioned earlier, several scholars in different contexts carried out a series of studies related to the act of congratulation. These studies deal with the realization and use of congratulation strategies but the issue of pragmatic transfer (PT) is not investigated so far. Therefore, in the present study, the researchers tried to investigate the concept of PT (pragmatic transfer) in the realization of congratulatory expressions employed by Punjabi EFL learners, which could be proved fruitful in order to fill in the gap in the area of research on speech act of congratulation in terms of Pragmatic Transfer. Since in Pakistani context, English language is treated as a subject rather than a particular language due to which the interest of both teachers and students is same that is, how to pass the exams. Due to which most significance is attributed to the lexical, grammatical and syntactic aspects of the language in case of teaching and learning as well. But due to the recent shift from the grammatical to communicative competence, the whole dimension of the research is changed. The researchers are trying to investigate the areas of speech acts with respect to the notion of transfer from L1 to L2 because the basic assumption in ILP studies is that the culture of learners' native language 
influences the learners' production of the target language. Though there are a number of studies conducted in the field of speech acts cross-linguistically by contrasting non-native with native performance. Within Pakistan, only a few studies (Saleem \& Uzma, 2018; Khan \& Sultana, 2014) are conducted related to this field and especially the area of pragmatic transfer is not accounted so far. It is hoped that the present study can highlight the significance of interlanguage pragmatics among EFL learners in order to acquire appropriate congratulation behavior, which will improve their performance in intercultural communication. Furthermore, the present study will prove significant because it will fill the gap in research on Speech acts in general and Pragmatic Transfer (PT) in particular within Pakistani context.

\subsection{Research Question}

For this purpose, the following research questions were developed.

1) What type of congratulation strategies are used by Punjabi EFL learners and Native English speakers?

2) What type of congratulation strategies are more likely said to be transferred pragmatically from L1 to L2 by Pakistan EFL learners?

3) How does the culture of L1 effect the realization of Congratulation strategies in L2?

\section{Research Methodology}

The focus of this study was to investigate pragmatic transfer realized by Punjabi EFL learners in the performance of the speech act of congratulations. For this purpose, a quantitative research design was used by the researchers keeping in view the quantitative nature and means of analysis of the data. A discourse completion (DCT) was used to collect data from participants and later scale response questionnaire (SRQ) was used to measure the perception of participants in terms of four contextual variables. The data was analyzed with the help of the chisquare test and co-relational test with the help of SPSS-21 software program.

\subsection{Participants}

The total number of participants, who participated in this study were 120, who were further divided into four different groups having 30 participants in each group, 30 Native English speakers, 30 Punjabi EFL learners of the elite class, 30 Punjabi EFL learners of the middle class and 30 Punjabi EFL learners of the lower class. The participants were heterogenous in nature, in terms of their cultural and academic background. The participants of this study were graduate and postgraduate students studying in their final years of the course of their studies. The Punjabi EFL learners and EL speakers, who participated in this study came from diverse majors including, M.Phil Language and Literature, Management Sciences, MA English Literature and Arts and BSC in Computer Sciences.

\subsection{Data Collection Tools}

Generally, it is suggested that multiple approaches (combination of two or more methods of data collection) should be used for the purpose of collection in cross-cultural and intercultural communication. Keeping in mind this view, a mixture of three data collection tools was used: (a) Demographic informative questionnaire, (b) a discourse completion test and (c) scaled- response questionnaire. For this purpose, a demographic informative questionnaire was used. A discourse completion test was used to collect production data. The DCT was comprised of 12 different situations based on two social variables namely societal power and distance and form six social combinations having two situations in each combination as illustrated in the following table:

Table 1. Representation of situations according to the contextual variable combinations

\begin{tabular}{lllllll}
\hline Contextual variable combinations & $(+\mathrm{p},+\mathrm{d})$ & $(=\mathrm{p},+\mathrm{d})$ & $(-\mathrm{p},+\mathrm{d})$ & $(+\mathrm{p},-\mathrm{d})$ & $(=\mathrm{p},-\mathrm{D})$ & $(-\mathrm{p},-\mathrm{d})$ \\
\hline Situations & $(\mathrm{S} 11, \mathrm{~S} 12)$ & $(\mathrm{S} 2, \mathrm{~S} 8)$ & $(\mathrm{S} 5, \mathrm{~S} 7)$ & $(\mathrm{S} 1, \mathrm{~S} 6)$ & $(\mathrm{S} 3, \mathrm{~S} 9)$ & $(\mathrm{S} 4, \mathrm{~S} 10)$ \\
\hline
\end{tabular}

Note. $\mathrm{p}=$ Social Power, $\mathrm{d}=$ Social Distance $-\mathrm{p}$ (Speaker has less power), $+\mathrm{p}$ (Speaker has greater power), $=\mathrm{p}$ (Speaker and hearer have equal power), $+\mathrm{d}$ (Interlocutors unfamiliar to each other), -d (Interlocutors familiar to each other).

Scale-Response Questionnaire was used for the collection of perception data, which is considered as the sociopragmatic knowledge of the speaker. The SRQ was based on four contextual variables: the degree of familiarity between the interlocutors, social power, the degree of difficulty in the production of congratulations and the degree of obligation in carrying out congratulations. 


\subsection{Data Collection Procedure}

The participants who showed their willingness to participate in the study were asked to complete a DIQ and later they were asked to consider all the instructions mentioned for filling a DCT and SRQ in order to give their responses as they all were in real-life contexts and were also asked to be as natural in their responses as possible. The DIQ, DCT, and SRQ were sent through E-mail to a colleague in the UK in order to collect data from native English speakers. All the information related to the purpose of the study and how to administer the tool was explained to that colleague in detail, while within Pakistani context the participants were accessed personally by researcher and his colleague at Bahria University, MUST and the University Of Gujarat, Pakistan.

\subsection{Data Analysis Procedure}

The data obtained from DCT and SRQ was coded and analyzed in the light of the taxonomy of Elwood's (2004) congratulation strategies [R.5] listed below.

Table 2. Classification of congratulation strategies

\begin{tabular}{ll}
\hline Names of strategies & Instances of Congratulations \\
\hline 1. Illocutionary Force Indicating Device & Congrats Congratulations dear \\
2. Expression of happiness & I am so happy to hear this It's amazing \\
3. Request for information & Are you satisfied with your marriage now? \\
4. Expression of Validation & you deserve it I know you are capable of \\
5. Self-related comments & Longings, Jealousy, Forecasting \\
6. Expression of surprise & really! Wao! What! \\
7. An offer of good wish & I wish you happy married life \\
8. Encouragement & You should work hard if you want to achieve your goals \\
9. Joking & Are you kidding \\
10. Affection Expressions & I am always with you \\
11. A suggestion of celebration & let's go out for a treat \\
12. Thanking God & Thanks to God \\
13. Offer of help & I wish I can help you \\
14. assessing the situation negatively & Why did you get engaged? \\
\hline
\end{tabular}

The encoded data was subjected to statistical analysis. The percentage and raw frequency test along with the correlational test were used to measure the data. The criteria for the analysis of data was based on the following assumption made by the researchers, if there was the difference between the responses of both groups (Punjabi EFL learners and Native speakers) then the negative pragmatic transfer was operational and vice versa.

\section{Results and Analysis}

The expected number of responses through the discourse completion test were 1440 from 120 participants, which were further divided into four different groups of samples, 30 participants in each group. The total number of responses expected from the 30 participants of NE speaker was 360 and the responses obtained were recorded as $347(96 \%)$, while $13(3 \%)$ number of the responses were short (participants did not give responses in certain situations). Similarly, the total number of expected responses from the 30 participants of Punjabi EFL leaner (Elite class) was 360, out of which $327(90 \%)$ responses were obtained and 33(10\%) responses from 30 participants were recorded as short. In addition to this, the number of expected responses from 30 participants of Punjabi EFL learners (Middle class) was 360, while 316 (87\%) responses were yielded and 44 (13\%) responses were noticed as short. Furthermore, the expected number of total responses of Punjabi EFL learners (Lower class) was 360 , out of which $319(89 \%)$ responses were obtained and $41(11 \%)$ responses were recorded as short. The summary of the total expected, obtained and short responses could be illustrated as,

Total number of expected responses of 120 participants $=120 \times 12=1440$

Total number of obtained responses of 120 participants $=347+327+316+319=1309$

Total number of short responses of 120 participants $=13+33+44+41=131(9.1 \%)$

Data were analyzed in the light of proposed research questions.

Q.1.what are the different types of congratulation strategies used by Punjabi EFL learners and Native English speaker? 
The analysis of data related to this question was illustrated in the table given below based on the percentages of use of each strategy employed by the tetra groups of the participants in respect of each situation designed in the DCT.

Table 3. Percentage results for the use congratulation strategies

\begin{tabular}{|c|c|c|c|c|c|c|c|c|c|c|c|}
\hline \multirow{2}{*}{ Situations } & \multirow{2}{*}{ Participants } & \multicolumn{10}{|c|}{ Congratulation Strategies } \\
\hline & & RFI & IFID & OOGW & $\mathrm{EOH}$ & EOV & EOS & EOE & SOC & Encourage & Overlap \\
\hline \multirow[t]{4}{*}{ Situation.1 } & UK & $11 \%$ & $11 \%$ & $22 \%$ & $15 \%$ & $4 \%$ & $4 \%$ & $4 \%$ & $0 \%$ & $15 \%$ & $15 \%$ \\
\hline & $\mathrm{BU}$ & $15 \%$ & $31 \%$ & $27 \%$ & $4 \%$ & $4 \%$ & $8 \%$ & $8 \%$ & $8 \%$ & $4 \%$ & $0 \%$ \\
\hline & MUST & $5 \%$ & $55 \%$ & $20 \%$ & $5 \%$ & $5 \%$ & $0 \%$ & $0 \%$ & $0 \%$ & $5 \%$ & $5 \%$ \\
\hline & UOG & $14 \%$ & $29 \%$ & $4 \%$ & $11 \%$ & $4 \%$ & $4 \%$ & $4 \%$ & $4 \%$ & $4 \%$ & $29 \%$ \\
\hline \multirow[t]{4}{*}{ Situation.2 } & UK & $19 \%$ & $13 \%$ & $23 \%$ & $10 \%$ & $0 \%$ & $3 \%$ & $0 \%$ & $0 \%$ & $10 \%$ & $13 \%$ \\
\hline & $\mathrm{BU}$ & $8 \%$ & $17 \%$ & $33 \%$ & $8 \%$ & $8 \%$ & $8 \%$ & $4 \%$ & $0 \%$ & $4 \%$ & $8 \%$ \\
\hline & MUST & $0 \%$ & $32 \%$ & $4 \%$ & $8 \%$ & $20 \%$ & $8 \%$ & $4 \%$ & $0 \%$ & $0 \%$ & $24 \%$ \\
\hline & UOG & $8 \%$ & $32 \%$ & $16 \%$ & $8 \%$ & $4 \%$ & $4 \%$ & $4 \%$ & $0 \%$ & $4 \%$ & $20 \%$ \\
\hline \multirow[t]{4}{*}{ Situation. 3} & UK & $11 \%$ & $7 \%$ & $30 \%$ & $15 \%$ & $0 \%$ & $0 \%$ & $0 \%$ & $0 \%$ & $7 \%$ & $30 \%$ \\
\hline & $\mathrm{BU}$ & $7 \%$ & $15 \%$ & $22 \%$ & $11 \%$ & $4 \%$ & $7 \%$ & $0 \%$ & $4 \%$ & $4 \%$ & $7 \%$ \\
\hline & MUST & $3 \%$ & $20 \%$ & $0 \%$ & $10 \%$ & $0 \%$ & $13 \%$ & $0 \%$ & $3 \%$ & $3 \%$ & $20 \%$ \\
\hline & UOG & $8 \%$ & $32 \%$ & $8 \%$ & $8 \%$ & $4 \%$ & $8 \%$ & $8 \%$ & $4 \%$ & $4 \%$ & $16 \%$ \\
\hline \multirow[t]{4}{*}{ Situation. 4} & UK & $7 \%$ & $21 \%$ & $21 \%$ & $7 \%$ & $7 \%$ & $0 \%$ & $0 \%$ & $7 \%$ & $10 \%$ & $7 \%$ \\
\hline & $\mathrm{BU}$ & $8 \%$ & $8 \%$ & $25 \%$ & $0 \%$ & $0 \%$ & $4 \%$ & $8 \%$ & $8 \%$ & $13 \%$ & $13 \%$ \\
\hline & MUST & $6 \%$ & $68 \%$ & $9 \%$ & $0 \%$ & $0 \%$ & $0 \%$ & $9 \%$ & $0 \%$ & $0 \%$ & $14 \%$ \\
\hline & UOG & $0 \%$ & $40 \%$ & $7 \%$ & $10 \%$ & $3 \%$ & $0 \%$ & $0 \%$ & $7 \%$ & $3 \%$ & $36 \%$ \\
\hline \multirow[t]{4}{*}{ Situation.5 } & UK & $5 \%$ & $7 \%$ & $18 \%$ & $11 \%$ & $7 \%$ & $7 \%$ & $7 \%$ & $7 \%$ & $21 \%$ & $7 \%$ \\
\hline & $\mathrm{BU}$ & $13 \%$ & $20 \%$ & $17 \%$ & $13 \%$ & $3 \%$ & $0 \%$ & $3 \%$ & $7 \%$ & $13 \%$ & $10 \%$ \\
\hline & MUST & $0 \%$ & $55 \%$ & $7 \%$ & $7 \%$ & $7 \%$ & $0 \%$ & $0 \%$ & $0 \%$ & $3 \%$ & $21 \%$ \\
\hline & UOG & $7 \%$ & $32 \%$ & $4 \%$ & $7 \%$ & $7 \%$ & $0 \%$ & $4 \%$ & $4 \%$ & $7 \%$ & $29 \%$ \\
\hline \multirow[t]{4}{*}{ Situation.6 } & UK & $10 \%$ & $10 \%$ & $28 \%$ & $21 \%$ & $3 \%$ & $7 \%$ & $3 \%$ & $3 \%$ & $7 \%$ & $7 \%$ \\
\hline & $\mathrm{BU}$ & $18 \%$ & $23 \%$ & $18 \%$ & $18 \%$ & $0 \%$ & $5 \%$ & $0 \%$ & $5 \%$ & $14 \%$ & $0 \%$ \\
\hline & MUST & $0 \%$ & $30 \%$ & $10 \%$ & $35 \%$ & $0 \%$ & $15 \%$ & $0 \%$ & $0 \%$ & $0 \%$ & $10 \%$ \\
\hline & UOG & $0 \%$ & $36 \%$ & $9 \%$ & $9 \%$ & $5 \%$ & $0 \%$ & $5 \%$ & $5 \%$ & $5 \%$ & $27 \%$ \\
\hline \multirow[t]{4}{*}{ Situation.7 } & UK & $20 \%$ & $20 \%$ & $20 \%$ & $7 \%$ & $0 \%$ & $13 \%$ & $3 \%$ & $3 \%$ & $13 \%$ & $7 \%$ \\
\hline & $\mathrm{BU}$ & $15 \%$ & $15 \%$ & $15 \%$ & $7 \%$ & $4 \%$ & $4 \%$ & $4 \%$ & $0 \%$ & $11 \%$ & $26 \%$ \\
\hline & MUST & $0 \%$ & $45 \%$ & $7 \%$ & $17 \%$ & $0 \%$ & $0 \%$ & $3 \%$ & $0 \%$ & $0 \%$ & $28 \%$ \\
\hline & UOG & $0 \%$ & $36 \%$ & $9 \%$ & $9 \%$ & $0 \%$ & $5 \%$ & $0 \%$ & $9 \%$ & $5 \%$ & $23 \%$ \\
\hline \multirow[t]{4}{*}{ Situation. 8} & UK & $13 \%$ & $17 \%$ & $20 \%$ & $13 \%$ & $7 \%$ & $3 \%$ & $7 \%$ & $3 \%$ & $7 \%$ & $10 \%$ \\
\hline & $\mathrm{BU}$ & $14 \%$ & $20 \%$ & $27 \%$ & $10 \%$ & $0 \%$ & $13 \%$ & $0 \%$ & $0 \%$ & $7 \%$ & $10 \%$ \\
\hline & MUST & $4 \%$ & $16 \%$ & $4 \%$ & $28 \%$ & $0 \%$ & $4 \%$ & $4 \%$ & $0 \%$ & $0 \%$ & $40 \%$ \\
\hline & UOG & $8 \%$ & $40 \%$ & $8 \%$ & $8 \%$ & $4 \%$ & $8 \%$ & $4 \%$ & $0 \%$ & $4 \%$ & $16 \%$ \\
\hline \multirow[t]{4}{*}{ Situation.9 } & UK & $7 \%$ & $10 \%$ & $21 \%$ & $3 \%$ & $7 \%$ & $0 \%$ & $16 \%$ & $16 \%$ & $10 \%$ & $14 \%$ \\
\hline & $\mathrm{BU}$ & $11 \%$ & $26 \%$ & $37 \%$ & $4 \%$ & $0 \%$ & $4 \%$ & $0 \%$ & $0 \%$ & $0 \%$ & $4 \%$ \\
\hline & MUST & $0 \%$ & $14 \%$ & $10 \%$ & $7 \%$ & $3 \%$ & $0 \%$ & $21 \%$ & $21 \%$ & $0 \%$ & $41 \%$ \\
\hline & UOG & $11 \%$ & $33 \%$ & $7 \%$ & $11 \%$ & $4 \%$ & $4 \%$ & $0 \%$ & $0 \%$ & $0 \%$ & $21 \%$ \\
\hline \multirow[t]{4}{*}{ Situation.10 } & UK & $7 \%$ & $10 \%$ & $30 \%$ & $10 \%$ & $3 \%$ & $3 \%$ & $7 \%$ & $3 \%$ & $13 \%$ & $13 \%$ \\
\hline & BU & $30 \%$ & $13 \%$ & $13 \%$ & $17 \%$ & $0 \%$ & $0 \%$ & $3 \%$ & $0 \%$ & $0 \%$ & $23 \%$ \\
\hline & MUST & $14 \%$ & $21 \%$ & $21 \%$ & $3 \%$ & $0 \%$ & $0 \%$ & $0 \%$ & $0 \%$ & $0 \%$ & $41 \%$ \\
\hline & UOG & $13 \%$ & $27 \%$ & $10 \%$ & $13 \%$ & $10 \%$ & $0 \%$ & $3 \%$ & $0 \%$ & $0 \%$ & $23 \%$ \\
\hline \multirow[t]{4}{*}{ Situation.11 } & UK & $13 \%$ & $20 \%$ & $27 \%$ & $13 \%$ & $3 \%$ & $7 \%$ & $3 \%$ & $3 \%$ & $7 \%$ & $10 \%$ \\
\hline & $\mathrm{BU}$ & $13 \%$ & $10 \%$ & $17 \%$ & $3 \%$ & $0 \%$ & $0 \%$ & $0 \%$ & $0 \%$ & $20 \%$ & $23 \%$ \\
\hline & MUST & $7 \%$ & $38 \%$ & $10 \%$ & $0 \%$ & $0 \%$ & $0 \%$ & $0 \%$ & $0 \%$ & $17 \%$ & $28 \%$ \\
\hline & UOG & $0 \%$ & $30 \%$ & $7 \%$ & $4 \%$ & $4 \%$ & $0 \%$ & $0 \%$ & $0 \%$ & $11 \%$ & $26 \%$ \\
\hline \multirow[t]{4}{*}{ Situation.12 } & UK & $13 \%$ & $20 \%$ & $27 \%$ & $3 \%$ & $3 \%$ & $3 \%$ & $3 \%$ & $3 \%$ & $13 \%$ & $10 \%$ \\
\hline & $\mathrm{BU}$ & $13 \%$ & $10 \%$ & $17 \%$ & $7 \%$ & $3 \%$ & $10 \%$ & $0 \%$ & $0 \%$ & $27 \%$ & $13 \%$ \\
\hline & MUST & $7 \%$ & $38 \%$ & $10 \%$ & $3 \%$ & $0 \%$ & $7 \%$ & $0 \%$ & $0 \%$ & $7 \%$ & $28 \%$ \\
\hline & UOG & $0 \%$ & $30 \%$ & $7 \%$ & $7 \%$ & $7 \%$ & $3 \%$ & $7 \%$ & $7 \%$ & $7 \%$ & $27 \%$ \\
\hline
\end{tabular}

Note. $\%=$ percentage value of the responses, RFI= Request for information, IFID= Illocutionary force indicating a device, OOGW=Offer of a good wish, $\mathrm{EOH}=$ Expression of happiness, EOV= Expression of validation, EOS=Expression of surprise, EOE=Expression of envy, $\mathrm{SOC}=$ Suggestion of celebration. 
As illustrated in above table, there was shown mark differences found in respect of each and every situation in terms of percentage and most types of used strategies were, IFID, request for information, an expression of happiness, an offer of good wish, an expression of validation, expression of surprise, expression of envy, suggestion for celebration, encouragement and overlapped strategies.

Q.2. what types of congratulation strategies are more likely said to be transferred pragmatically from L1 to L2 by Pakistan EFL learners?

As discussed in the above section the points of differences in the use of strategies were used to show the existence of pragmatic transfer, therefore from the analysis of data the points of differences were marked to show that pragmatic transfer operates. The positive pragmatic transfer was based on the similarities and the negative pragmatic difference was based on the sharp points of differences between the responses of the participants. As illustrated in the table below.

Table 4. Results for the point of differences among the responses of NE speaker and Punjabi EFL learners (middle class)

\begin{tabular}{|c|c|c|c|c|c|}
\hline \multirow[t]{2}{*}{ Names of strategies } & \multicolumn{2}{|c|}{$\mathrm{NE}$} & \multicolumn{2}{|c|}{ PEFL } & \multirow{2}{*}{$\begin{array}{l}\text { Point of differences } \\
\% \text { age }\end{array}$} \\
\hline & $\mathrm{F}$ & \%age & $\mathrm{F}$ & \%age & \\
\hline 1.RFI & 38 & $11 \%$ & 13 & $4 \%$ & $6 \%$ \\
\hline 2.IFID & 48 & $14 \%$ & 103 & $33 \%$ & $19 \% \mathrm{PT}$ \\
\hline 3.OOWG & 83 & $24 \%$ & 35 & $11 \%$ & $13 \% \mathrm{PT}$ \\
\hline 4.EOH & 39 & $11 \%$ & 30 & $9 \%$ & $2 \%$ \\
\hline 5.EOV & 12 & $3 \%$ & 14 & $4 \%$ & $1 \%$ \\
\hline 6.EOS & 17 & $5 \%$ & 13 & $4 \%$ & $1 \%$ \\
\hline 7.EOE & 17 & $5 \%$ & 9 & $3 \%$ & $2 \%$ \\
\hline 8.SOC & 13 & $4 \%$ & 7 & $2 \%$ & $2 \%$ \\
\hline 9.Encouragement & 39 & $11 \%$ & 10 & $3 \%$ & $9 \%$ \\
\hline 10.Overlapped & 41 & $12 \%$ & 82 & $26 \%$ & $14 \% \mathrm{PT}$ \\
\hline
\end{tabular}

As shown in the table, the sharp difference was found between the use of the strategy of IFID among NE speaker and Punjabi EFL learners which was recorded as 19\%. The "Negative pragmatic transfer" was operational in the strategy of IFID, later the sharp difference was recorded at $13 \%$ which also indicated the existence of "Negative pragmatic transfer" and also in the use of the strategies of "overlapped expressions", "request of information" and "encouragement of congratulations strategies which yielded $14 \%, 6 \%$ and $9 \%$ respectively. The Negative expression transfer was seemed operational in the responses of NE speaker and Punjabi EFL learners (middle class).

The DCT data was further analyzed in the light of four contextual variables shaped in SRQ in order to examine the perception of the speech acts of congratulation. These four contextual variables were discussed one by one. First, the results related to the degree of familiarity were discussed followed by social power, difficulty, and obligation in expressing congratulations.

The results of the contextual variable (social distance) in respect of the degree of intimacy and unfamiliarity between the participants (Native and Punjabi EFL (Elite, Middle, and Lower class) learners were represented in the table at next page;

Table 5. Raw frequency and percentage results of the degree of familiarity

\begin{tabular}{lllll}
\hline Social Distance & NES & \multicolumn{3}{c}{ PEFL Learners } \\
\cline { 2 - 4 } & Frequency & \%age & Frequency & \%age \\
\hline Familiar & 156 & $47 \%$ & 159 & $50 \%$ \\
Unfamiliar & 181 & $53 \%$ & 160 & $50 \%$ \\
\hline Note. $-\mathrm{d}=$ Familiar mean & 190 social distance between the interlocutors, $+\mathrm{d}=$ Unfamiliar means social distance is operational between the \\
interlocutors, NES, native English speaker and, PEFL = Punjabi English foreign language learners, frequency and \%: average.
\end{tabular}

It was evident from the above table that native English speaker and Punjabi EFL learner are at variance in their response to the comprehension of social distance. In respect of the degree of familiarity and unfamiliarity, $3 \%$ of the rate was identified as the rate of difference between the native and Punjabi EFL learner. This point of 
difference indicated that negative pragmatic transfer was operational because the cultural elements of the Punjabi EFL learner were operational. As for the rating of the degree of familiarity concerned, the native English speaker and Punjab EFL learner marked similar rate of familiarity expect of Punjab EFL learners (Lower-class), the participant rated the social status of interlocutors in the term as power (contextual variable). Native speakers Responses (power of the speaker on the hearer). As shown in the following table, rated higher social power which was recorded as $37 \%$ in the social category of $\mathrm{C} 4$ including. The situations and the responses in the social power rated as lower constituted $36 \%$ of the total responses in the social category of C6 including the situations and some of the participants assessed the social power at equal level means both the heart and the speakers has no over each other. The summary of the results of social power was given in the following table.

Table 6. Raw frequency and percentage results of the degree of social power

\begin{tabular}{lllllll}
\hline Participants & $+\mathrm{p}$ & & $\mathrm{p}$ & & $\mathrm{p}$ & \\
\cline { 2 - 7 } & $\mathrm{F}$ & $\%$ & $\mathrm{~F}$ & $\%$ & $\mathrm{~F}$ & 0 \\
\hline NES & 114 & $26 \%$ & 120 & $24 \%$ & 126 & $26 \%$ \\
PEFLE & 121 & $27 \%$ & 125 & $25 \%$ & 114 & $23 \%$ \\
PEFLM & 110 & $25 \%$ & 123 & $24 \%$ & 127 & $26 \%$ \\
PEFLL & 96 & $22 \%$ & 140 & $28 \%$ & 124 & $25 \%$ \\
Total & 441 & $39 \%$ & 508 & $45 \%$ & 491 & $43 \%$ \\
\hline
\end{tabular}

Note. $+\mathrm{p}=$ higher power of the speaker, $=\mathrm{p}$ demonstrated the equal power of the speaker, $-\mathrm{p}$ represented less power of the speaker, NES $=$ Native English speaker, PEFLE $=$ Punjabi EFL learners (Elite class), PEFLM= Punjabi EFL learners (Middle class) and PEFLL $=$ Punjabi EFL learners (lower class).

In the following table, the rate of difficulty according to six societal combination C6 (-p, -d) was elaborated in which the rate of difficulty faced by the carrier of congratulation category was higher than the rate of no difficulty. All participants showed significant agreement in respect of their evaluation of the contextual factor of "Difficulty in expressing congratulations." In $\mathrm{C} 1(+\mathrm{p},+\mathrm{d})$ the Punjabi EFL learner orated difficulty higher than the native ES, which the influence of their particular culture.

Table 7. Raw frequency and percentage result for the degree of difficulty

\begin{tabular}{lllllllll}
\hline \multirow{2}{*}{$\begin{array}{l}\text { Contextual } \\
\text { variables }\end{array}$} & NE & (f) & $(\%)$ & PEFLE & PEFLM & PEFLL \\
\hline Difficulty & 153 & $25 \%$ & 162 & $27 \%$ & 120 & $20 \%$ & $(\mathrm{f})$ & $(\%)$ \\
No difficulty & 207 & $26 \%$ & 198 & $22 \%$ & 240 & $29 \%$ & 186 & $27 \%$ \\
\hline
\end{tabular}

Akin to their elevation of the addresser's difficulty in expressing the speech act of "Congratulation", there was not found any sharp between each group of the participants. The person correlation analysis was performed to determine the degree of carrying out the Congratulations on the particular contact of happiness. The correlation was signified at 0.01 level as shown in figure (see Appendix A).

\begin{tabular}{|c|c|c|c|c|c|}
\hline \multicolumn{6}{|c|}{ Correlations } \\
\hline & & UK & BU & MUST & UOG \\
\hline \multirow[t]{3}{*}{ UK } & Pearson Correlation & 1 & $1.000^{* n}$ & $1.000^{n}$ & $1.000^{N}$ \\
\hline & Sig. (2-talled) & & . & . & . \\
\hline & $\mathrm{N}$ & 2 & 2 & 2 & 2 \\
\hline \multirow[t]{3}{*}{ BU } & Pearson Correlation & $1.000^{n \pi}$ & 1 & $1.000^{n x}$ & $1.000^{\times n}$ \\
\hline & Sig. (2-tailed) & . & & . & . \\
\hline & $\mathrm{N}$ & 2 & 2 & 2 & 2 \\
\hline \multirow[t]{3}{*}{ MUST } & Pearson Correlation & $1.000^{n-}$ & $1.000^{* *}$ & 1 & $1.000^{* *}$ \\
\hline & Sig. (2-tailed) & . & . & & . \\
\hline & $\mathrm{N}$ & 2 & 2 & 2 & 2 \\
\hline \multirow[t]{3}{*}{ UOG } & Pearson Correlation & $1.000^{* x}$ & $1.000^{* x}$ & $1.000^{x x}$ & 1 \\
\hline & Sig. (2-tailed) & . & . & . & \\
\hline & $\mathrm{N}$ & 2 & 2 & 2 & 2 \\
\hline
\end{tabular}

Figure 1. Results of correlation among both NE speaker and Punjabi EFL learner 


\section{Conclusion}

The correlation result of all responses including NE speakers (UK) and Punjabi (EFL) learners (Elite, BU), middle (must) and lower(UOG) was illustrated in the table. It was evident from the table that, the both group's native speakers and non-native speakers were at variance with each other is farther. Such as, the participants of Punjabi (EFL) learners (Elite class) were at difference from NE speaker but that they are closely related with the responses of NE speakers, which was marked sharp difference from the EFL speaker which was recorded at .196* level of person correlation (2-tailed), which showed that Punjabi EFL learners (Middle class) deviate from the rule of the target language and culture. In addition to this, the Punjabi EFL learners (lower class) were relatively at sharp differences from NE speaker as compared to both Elite and Middle-class Punjabi EFL learners, which was recorded at $.249^{*}$ level of Pearson correlation(2-tailed) as represented in the table at next page. Anyhow, the notion of pragmatic difference was discussed as illustrated in the results section was based on the points of differences between the participants. There were three strategies which demonstrated sharp difference which is not negligible and showed the existence of negative pragmatic transfer, an offer of a good wish, IFID, and overlapped strategies respectively while the other mentioned strategies show the existence of positive pragmatic transfer, which shows that Punjabi EFL learners are at the advanced level of their L2 competence. More significantly the result revealed a significant difference between the participants comprehension of these contextual variable Out of these 4 situational variables, the degree of speaker power is noted operational in causing the variation among the participants realization of perception knowledge of the language which they are accusing and the degree of obligation in carrying out the congratulatory linguistic behavior seemed to cause the minimal variation among the NE speaker and PEFL participants. From the findings of the all proposed research question it became evident that there was slightly different between the realization of speech act of congratulations of NE speaker and Punjabi EFL learner but there were some strategies which showed negative pragmatic transfer existence which was caused due to the cultural impacts of both participants, which supports the assumption of ILP studies, which posit that the culture of NE speaker has effects over the use of L2 pragmatic rules in regard of the realization of speech acts.

\section{References}

Austin, J. L. (1962). How to do things with words. Oxford: Oxford University Press.

Barna, L. M. (1994). Stumbling blocks in intercultural communication. Intercultural communication: A reader, 6 , 345-353.

$\mathrm{Bu}$, J. (2011). A study of pragmatic transfer in suggestion strategies by Chinese learners of English. Studies in Literature and Language, 3(2), 28.

Elwood, K. (2004). “Congratulations!”: A Cross-Cultural Analysis of Responses to Another's Happy News. Journal of Pragmatics, (25), 355-386.

Hashemian, M. (2012). Cross-cultural differences and pragmatic transfer in English and Persian refusals. Journal of Teaching Language Skills, 31(3), 23-46.

Jiang, L. (2015). An empirical study on pragmatic transfer in refusal speech act produced by Chinese high school EFL learners. English Language Teaching, 8(7), 95. https://doi.org/10.5539/elt.v8n7p95

Kasper, G. (1992). Pragmatic transfer. Interlanguage studies bulletin (Utrecht), 8(3), 203-231. https://doi.org/10.1177/026765839200800303

Kasper, G. (2000). Data collection in pragmatics research. Culturally speaking: Managing rapport through talk across cultures, 316341.

Kasper, G., \& Rose, K. R. (1999). Pragmatics and SLA. Annual review of applied linguistics, 19, 81-104. https://doi.org/10.1017/S0267190599190056

Leech, G. N. (1983). Principles of Pragmatics. London: Longman Group Ltd.

Saleem, T., \& Anjum, U. (2018). Positive and negative politeness: A crosscultural study of apology responses by British English and Pakistani Urdu speakers. International Journal of English Linguistics, 8(5). https://doi.org/10.5539/ijel.v8n5p71

Searle, J. R. (1969). Speech acts: An essay in the philosophy of language (Vol. 626). Cambridge university press. https://doi.org/10.1017/CBO9781139173438

Searle, J. R. (1976). A classification of illocutionary acts. Language in Society, 5(1), 1-23. https://doi.org/10.1017/S0047404500006837 
Selinker, L. (1972). Interlanguage. IRAL-International Review of Applied Linguistics in Language Teaching, 10(1-4), 209-232. https://doi.org/10.1515/iral.1972.10.1-4.209

Sultana, N., \& Khan, Q. (2014). Cultural effect of gender on apology strategies of Pakistani undergraduate students. NUML Journal of Critical Inquiry, 12(2), 24.

Thomas, J. (1983). Cross-cultural pragmatic failure. Applied linguistics, 4(2), 91-112. https://doi.org/10.1093/applin/4.2.91

Trosborg, A. (1995). Interlanguage pragmatics: Requests, complaints, and apologies (Vol. 7). Walter de Gruyter. https://doi.org/10.1515/9783110885286

Yarahmadi, A., \& Fathi, S. (2015). A Cross Cultural Study on Iranian EFL Students' Pragmatic Transfer. Procedia-Social and Behavioral Sciences, 192, 498-505. https://doi.org/10.1016/j.sbspro.2015.06.077

\section{Appendix A}

\section{(A) Demographic Informative Questionnaire}

Gender: M/F

Nationality:

Currently enrolled institution's name:

Course of Study:

Can you speak languages other than English:

Currently proficiency level of English:

\section{(B) Discourse Completion Task}

\section{Dear Participants,}

The aim of the present study is to investigate cross-cultural differences and pragmatic transfer in speech act behavior. It is not a kind of test in which your responses are marked right or wrong. This questionnaire consists of 15 situations. It is requested that please read all these situations very carefully and suppose that you are in the same situation and write in the responses. Please try to provide natural responses as you are in real life situations. If you have any problem, please don't feel shy. You are welcome to ask.

Thank you for giving your time.

Situation 1: You went to your class and your students inform you that one of the students in your class got a scholarship on the basis of which he is going to study abroad. That student isn't present in the class. Tomorrow you see that student standing in the corridor in front of the library. What will you say to him?

You:

Situation 2: You are traveling and one of the passengers sitting beside you received a phone call and he became very excited and happy. You asked him, what's up? He informed you that he is appointed as a surgeon in a government hospital. What will you say to him?

You:

Situation 3: You are working as a clerk in a company and you have been informed that one of your colleagues gets a promotion. How will you respond in this situation?

You:

Situation 4: You are an employee in a company and you have been informed that your employer got engaged recently. At afternoon, you see your employer. What will you say to him?

You: 
Situation 5: You an anchor person on the national news channel. Election held two days ago and newly elected Prime Minister comes in your studio for his first address to the nation. How you will respond to him on his success.

You:

Situation 6: You are a boss in an office. You have been informed that one of your employees has been blessed with a newborn baby after 10 years his/her marriage. How will you respond?

You:

Situation 7: You are working as a junior teacher in a university. Recently, new Head of English department appointed. At your first meeting with him/her, how you will respond to him/her at his/her appointment as a HOD.

You:

Situation 8: You are working for a company. While working in your office, one of the friends of your colleague comes and wants to talk to your colleague in the same office. There you have been informed by your colleague that his friend has become the managing director of the company. What will you say?

You:

Situation 9: One of your friends meets you after two months. You asked him, where he has been from last two months. Your friend tells you he has a big news for you, that he got a permanent job in the university. What will you say to him?

You:

Situation 10: You went to visit a place with your father. There your father sees his family doctor, whom he hasn't seen from a long period of time. Your father inquired from him about his absence. He informed that he got married five months ago. What will you say to him?

You:

Situation 11: You are a regional sports director and you are visiting a sports complex with your secretary. There he introduces you to a newly elected member of your regional sports team. What will you say to him about his selection?

You:

Situation 12: You are working as a dean at a university. You are called as a Chief Guest on the Annual Prize Distribution ceremony at another campus of the university in order to distribute awards among the topper of the university. How will you respond to him/her on his/her great achievement?

You:

\section{(C) Scaled-Response Questionnaire}

Scaled-Response Questionnaire is used for the assessment of contextual (social) variables. Please read each situation and rate the 4 variables on a scale of 1 to 5 . The number 1 is lowest and number 5 is highest. Circle the number which you consider is more appropriate.

Situation 1: You went to your class and your students inform you that one of the brilliant students of your class got a scholarship on the basis of which he is going to study abroad. That student isn't present in the class.

Tomorrow you see that student standing in the corridor in front of the library.

1) How much familiarity is there between the speaker and the hearer in this situation?

No familiarity high familiarity

$\begin{array}{lllll}1 & 2 & 3 & 4 & 5\end{array}$ 
2) How much power does the speaker have over the hearer in this situation?

No power

high power

$$
\begin{array}{lllll}
1 & 2 & 3 & 4 & 5
\end{array}
$$

3) How difficult is giving congratulation in this situation?

Not difficult

$$
\text { very difficult }
$$

$\begin{array}{lllll}1 & 2 & 3 & 4 & 5\end{array}$

4) What is the hearer's Obligation in carrying out the speech act of congratulation in this situation?

No obligation strong obligation

$$
\begin{array}{lllll}
1 & 2 & 3 & 4 & 5
\end{array}
$$

Situation 2: You are traveling and one of the passengers sitting beside you received a phone call and he became very excited and happy. You asked him, what's up? He informed you that he is appointed as a surgeon in a government hospital.

1) How much familiarity is there between the speaker and the hearer in this situation?

$$
\begin{array}{ccccc}
\text { No familiarity } & \multicolumn{3}{c}{\text { high familiarity }} \\
1 & 2 & 3 & 4 & 5
\end{array}
$$

2) How much power does the speaker have over the hearer in this situation?

No power high power

$\begin{array}{lllll}1 & 2 & 3 & 4 & 5\end{array}$

3) How difficult is giving congratulation in this situation?

Not difficult very difficult

$$
\begin{array}{lllll}
1 & 2 & 3 & 4 & 5
\end{array}
$$

4) What is the hearer's Obligation in carrying out the speech act of congratulation in this situation?

$\begin{array}{ccccc}\text { No obligation } & & & \text { strong obligation } \\ 1 & 2 & 3 & 4 & 5\end{array}$

Situation 3: You are working as a clerk in a company ad you have been informed that one of your colleagues gets a promotion.

1) How much familiarity is there between the speaker and the hearer in this situation?

No familiarity high familiarity

$\begin{array}{lllll}1 & 2 & 3 & 4 & 5\end{array}$

2) How much power does the speaker have over the hearer in this situation?

No power high power

$\begin{array}{lllll}1 & 2 & 3 & 4 & 5\end{array}$

3) How difficult is giving congratulation in this situation?

Not difficult very difficult

$$
\begin{array}{lllll}
1 & 2 & 3 & 4 & 5
\end{array}
$$

4) What is the hearer's Obligation in carrying out the speech act of congratulation in this situation?

No obligation

$$
1
$$
strong obligation

45

Situation 4: You are an employee in a company and you have been informed that your employer got engaged recently. At afternoon, you see your employer.

1) How much familiarity is there between the speaker and the hearer in this situation?

No familiarity

1 high familiarity 
2) How much power does the speaker have over the hearer in this situation?

No power

high power
1
23
4
5

3) How difficult is giving congratulation in this situation?

Not difficult

very difficult

$\begin{array}{lllll}1 & 2 & 3 & 4 & 5\end{array}$

4) What is the hearer's Obligation in carrying out the speech act of congratulation in this situation?

No obligation strong obligation

$$
\begin{array}{lllll}
1 & 2 & 3 & 4 & 5
\end{array}
$$

Situation 5. You can anchor person of the national news channel. Election held two days ago and newly elected Prime Minister comes in your studio for his first address to the nation. How you will respond to him on his success.

1) How much familiarity is there between the speaker and the hearer in this situation?

$\begin{array}{ccccc}\text { No familiarity } & & & \text { high familiarity } \\ 1 & 2 & 3 & 4 & 5\end{array}$

2) How much power does the speaker have over the hearer in this situation?

No power

high power

$\begin{array}{lllll}1 & 2 & 3 & 4 & 5\end{array}$

3) How difficult is giving congratulation in this situation?

Not difficult very difficult

$$
\begin{array}{lllll}
1 & 2 & 3 & 4 & 5
\end{array}
$$

4) What is the hearer's Obligation in carrying out the speech act of congratulation in this situation?

No obligation$$
1
$$

2 strong obligation

Situation 6: You are a boss in an office. You have been informed that one of your employee has been blessed with a newborn baby after 10 years his/her marriage.

1) How much familiarity is there between the speaker and the hearer in this situation?

No familiarity

high familiarity

$$
\begin{array}{lllll}
1 & 2 & 3 & 4 & 5
\end{array}
$$

2) How much power does the speaker have over the hearer in this situation?

No power high power

$\begin{array}{lllll}1 & 2 & 3 & 4 & 5\end{array}$

3) How difficult is giving congratulation in this situation?

Not difficult very difficult

$$
\begin{array}{lllll}
1 & 2 & 3 & 4 & 5
\end{array}
$$

4) What is the hearer's Obligation in carrying out the speech act of congratulation in this situation?

No obligation

$$
1
$$
strong obligation

Situation 7: You are working as a junior teacher in a university. Recently, new Head of English department appointed. At your first meeting with him/her, how you will respond to him/her at his/her appointment as a HOD.

1) How much familiarity is there between the speaker and the hearer in this situation?

No familiarity

1

high familiarity

$4 \quad 5$ 
2) How much power does the speaker have over the hearer in this situation?

No power

high power

$$
\begin{array}{lllll}
1 & 2 & 3 & 4 & 5
\end{array}
$$

3) How difficult is giving congratulation in this situation?

Not difficult

$$
\text { very difficult }
$$

$\begin{array}{lllll}1 & 2 & 3 & 4 & 5\end{array}$

4) What is the hearer's Obligation in carrying out the speech act of congratulation in this situation?

No obligation strong obligation

$$
\begin{array}{lllll}
1 & 2 & 3 & 4 & 5
\end{array}
$$

Situation 8: You are working for a company. While working in your office, one of the friends of your colleague comes and wants to talk to your colleague in the same office. There you have been informed by your colleague that his friend has become the managing director of the company.

1) How much familiarity is there between the speaker and the hearer in this situation?

$$
\begin{array}{cccccc}
\text { No familiarity } & \multicolumn{3}{c}{\text { high familiarity }} \\
1 & 2 & 3 & 4 & 5
\end{array}
$$

2) How much power does the speaker have over the hearer in this situation?

No power high power

$\begin{array}{lllll}1 & 2 & 3 & 4 & 5\end{array}$

3) How difficult is giving congratulation in this situation?

Not difficult very difficult

$$
\begin{array}{lllll}
1 & 2 & 3 & 4 & 5
\end{array}
$$

4) What is the hearer's Obligation in carrying out the speech act of congratulation in this situation?

No obligation strong obligation

$$
\begin{array}{lllll}
1 & 2 & 3 & 4 & 5
\end{array}
$$

Situation 9: One of your friends meets you after two months. You asked him, where he has been from last two months. Your friend tells you he has a big news for you, that he got a permanent job in the university.

1) How much familiarity is there between the speaker and the hearer in this situation?

No familiarity

$$
\text { high familiarity }
$$

$\begin{array}{lllll}1 & 2 & 3 & 4 & 5\end{array}$

2) How much power does the speaker have over the hearer in this situation?

No power high power

$\begin{array}{lllll}1 & 2 & 3 & 4 & 5\end{array}$

3) How difficult is giving congratulation in this situation?

Not difficult very difficult

$$
\begin{array}{lllll}
1 & 2 & 3 & 4 & 5
\end{array}
$$

4) What is the hearer's Obligation in carrying out the speech act of congratulation in this situation?

No obligation

$$
1
$$
strong obligation

45

Situation 10: You went to visit a pace with your father. There your father sees his family doctor, whom he hasn't seen from a long period of time. Your father inquired from him about his absence. He informed that he got married five months ago.

1) How much familiarity is there between the speaker and the hearer in this situation?

No familiarity

1 high familiarity

$4 \quad 5$


2) How much power does the speaker have over the hearer in this situation?

No power

high power

$\begin{array}{lllll}1 & 2 & 3 & 4 & 5\end{array}$

3) How difficult is giving congratulation in this situation?

Not difficult very difficult

$\begin{array}{lllll}1 & 2 & 3 & 4 & 5\end{array}$

4) What is the hearer's Obligation in carrying out the speech act of congratulation in this situation?

No obligation strong obligation

$$
\begin{array}{lllll}
1 & 2 & 3 & 4 & 5
\end{array}
$$

Situation 11: You are a regional sports director and you are visiting a sports complex with your secretary. There he introduces you to a newly elected member of your regional sports team.

1) How much familiarity is there between the speaker and the hearer in this situation?

$$
\begin{array}{ccccc}
\text { No familiarity } & & \multicolumn{3}{c}{\text { high familiarity }} \\
1 & 2 & 3 & 4 & 5
\end{array}
$$

2) How much power does the speaker have over the hearer in this situation?

No power high power

$\begin{array}{lllll}1 & 2 & 3 & 4 & 5\end{array}$

3) How difficult is giving congratulation in this situation?

Not difficult very difficult

$\begin{array}{lllll}1 & 2 & 3 & 4 & 5\end{array}$

4) What is the hearer's Obligation in carrying out the speech act of congratulation in this situation?

No obligation strong obligation

$$
\begin{array}{lllll}
1 & 2 & 3 & 4 & 5
\end{array}
$$

Situation 12: You are working as a dean at a university. You are called as a Chief Guest on the Annual Prize Distribution ceremony at another campus of the university in order to distribute awards among the topper of the university.

1) How much familiarity is there between the speaker and the hearer in this situation?

No familiarity

high familiarity

$\begin{array}{lllll}1 & 2 & 3 & 4 & 5\end{array}$

2) How much power does the speaker have over the hearer in this situation?

No power high power

$\begin{array}{lllll}1 & 2 & 3 & 4 & 5\end{array}$

3) How difficult is giving congratulation in this situation?

Not difficult very difficult

$$
\begin{array}{lllll}
1 & 2 & 3 & 4 & 5
\end{array}
$$

4) What is the hearer's Obligation in carrying out the speech act of congratulation in this situation?

No obligation

1

23

strong obligation

$4 \quad 5$

\section{Copyrights}

Copyright for this article is retained by the author, with first publication rights granted to the journal.

This is an open-access article distributed under the terms and conditions of the Creative Commons Attribution license (http://creativecommons.org/licenses/by/4.0/). 